Fotografia: Sílvia Aguião. Manifestação realizada durante a I Conferência Nacional LGBT (Brasília, 2008), denunciando a violência a que é submetida a população LGBT no Brasil.

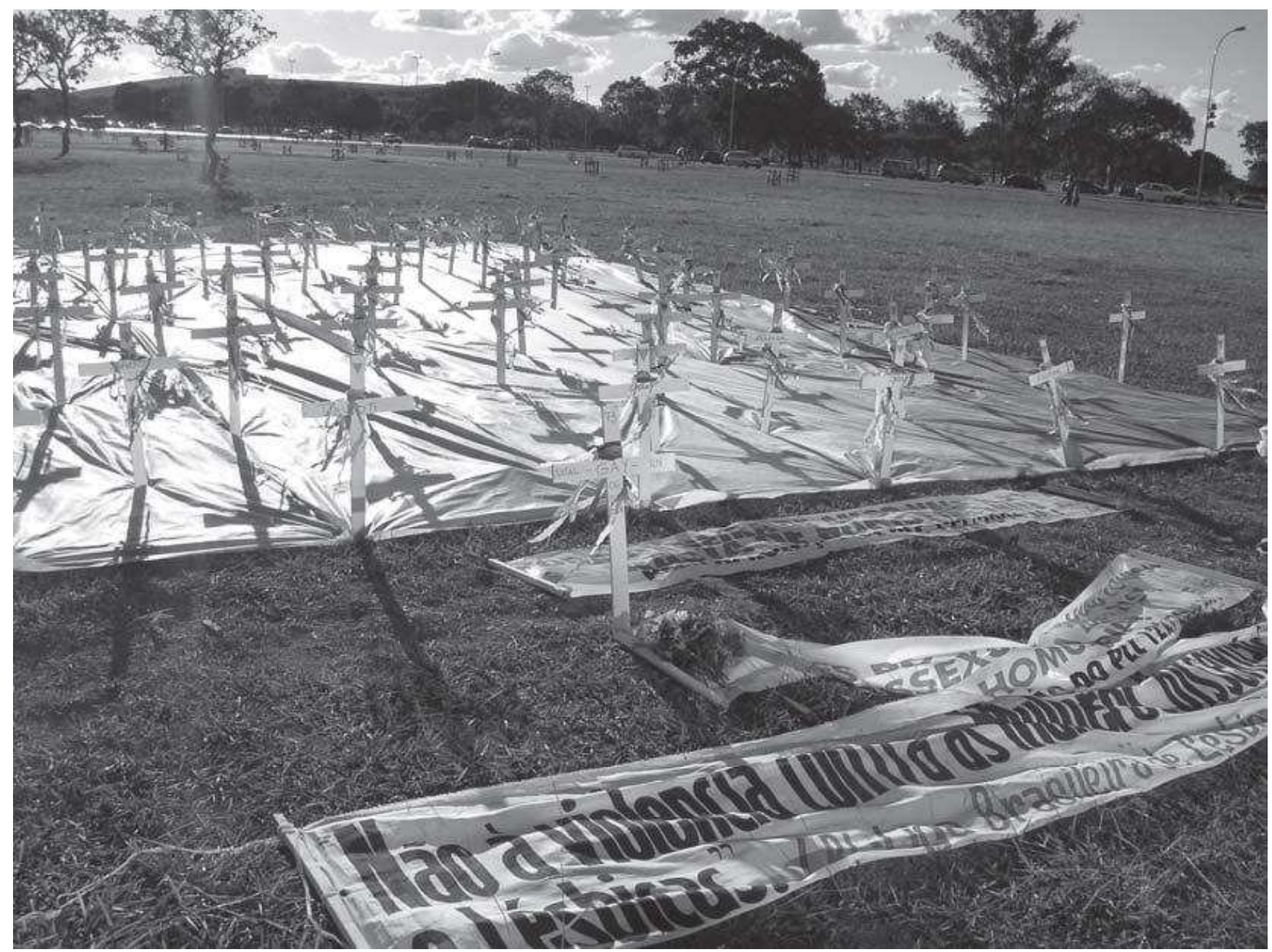




\title{
A invenção do dispositivo da transexualidade: produção de "verdades" e experiências trans
}

\author{
Maria de Fátima Lima Santos*
}

\begin{abstract}
Resumo: Partindo da ideia de dispositivo no pensamento de Michel Foucault, este artigo apresenta uma breve genealogia da transexualidade mapeando sua emergência e visibilidade, principalmente a partir da segunda metade do século XX. O objetivo central consiste em cartografar as diferentes classificações, caracterizações e intervenções que foram decisivas na construção da transexualidade enquanto uma "disforia de gênero" e/ou um "transtorno de identidade de gênero", reduzindo as possibilidades de expressões das transexualidades a uma patologia. Nesse sentido, a consolidação da norma psiquiátrica se constituiu a partir de diferentes redes relacionais envolvendo disputas de saberes, categorias científicas, relações de poder, diferentes práticas de intervenção, principalmente no campo europeu e norte-americano. No entanto, é possível perceber na contemporaneidade movimentos rumo a "despatologização" da transexualidade, exercício este que requer a compreensão da invenção da transexualidade, bem como as subversões normativas que compõem o dispositivo.
\end{abstract}

Palavras-chave: Dispositivo; transexualidade; norma psiquiátrica; subversões normativas.

Abstract: Starting from the idea of "dispositive" developed in the thinking of Michael Foucault this article presents a brief genealogy of transsexuality mapping its emergence and visibility especially from the second part of twenty century. The central goal consists in make cartography of different classifications, characterizations and interventions that was decisive in the construction of the idea of transsexuality as a "gender dysphoria" and/or a "gender identity disorder", reducing in this process the possibilities of transsexual expressions with the construction of pathology. In this way, it is necessary point out the consolidation of a psychiatric norm have been built up from different relationships networks that involves disputes of knowledge, scientific categories, power relations and interventional practices on the body and subjectivities, mainly in Europe and North America. Nevertheless we can notice a contemporary movement toward the "depathologization" of transsexuality, this exercise requires an understanding of the invention of transsexuality and the the normative subversions that make up the dispositive.

Keyword: Dispositive; transsexuality; standard psychiatric; normative subversions.

\footnotetext{
* Antropóloga, doutora em Saúde Coletiva pelo Instituto de Medicina Social da Universidade do Estado do Rio de Janeiro (IMS/UERJ) e professora adjunta da Universidade Federal do Rio de Janeiro (UFRJ/Macaé). E-mail: fatimalima @macae.ufrj.br
} 


\section{heVistg all pgutg}

\} A INVENÇÃO DO DISPOSITIVO DA TRANSEXUALIDADE - SANTOS, M. F. L. \}

\section{Apresentação}

Tomando como referência a definição e a discussão de "dispositivo" no pensamento de Michel Foucault, a preocupação central do artigo reside em compreender como a transexualidade, ao longo do século XX, transformou-se em uma patologia expressa através de uma norma psiquiátrica.

A ideia dos dispositivos de controle é um dos elementos conceituais centrais na obra de Michel Foucault. Seus estudos voltados para a passagem da soberania ao biopoder (poder sobre a vida) e a consolidação das sociedades disciplinares revelaram inúmeros processos de assujeitamentos (submissão dos sujeitos às normas). Para Foucault (2002), os dispositivos podem se apresentar através de três possibilidades:

em primeiro lugar, um conjunto decididamente heterogêneo que engloba discursos, instituições, organizações arquitetônicas, decisões regulamentares, leis, medidas administrativas, enunciados científicos, proposições filosóficas, morais filantrópicas. Em suma, o dito e o não dito são elementos do dispositivo. O dispositivo é a rede que se pode estabelecer entre estes elementos. Em segundo lugar, gostaria de demarcar a natureza da relação que pode existir entre estes elementos heterogêneos. Sendo assim, tal discurso pode aparecer como programa de uma instituição ou, ao contrário, como elemento que permite justificar e mascarar uma prática que permanece muda; pode ainda funcionar como uma reinterpretação dessa prática, dando acesso a um novo campo de racionalidade. Em suma, entre esses elementos discursivos ou não, existe um tipo de jogo, ou seja, modificações de funções, que também podem ser muito diferentes. Em terceiro lugar, entendo dispositivo como um tipo de formação que, em um determinado momento histórico, teve como função principal responder a uma urgência. O dispositivo tem, portanto, uma função estratégica dominante (FOUCAULT, 2002, p. 244).

Partindo dessa caracterização, no âmbito dos mesmos, encontram-se estruturas arquitetônicas (igrejas, escolas, prisões, instituições sociais, entre outros), normas, regulamentos, leis, postulados, proposições morais, éticas, estéticas, entre outras formas de controle e resistências cuja heterogeneidade é caracterizada pela capacidade de unir pontos, estabelecer conexões, formar redes, configurando racionalidade a determinado campo, seja ele material ou discursivo. Dessa forma, os dispositivos se articulam e produzem, em determinados momentos históricos, a função estratégica de produção e sustentação de regimes de verdades. Foi assim com a sexualidade a partir dos séculos XVIII e XIX, e foi assim com a transexualidade a partir das primeiras décadas do século XX e, mais precisamente, sua segunda metade.

Deleuze (1990), discutindo o conceito de "dispositivo" no pensamento de Michel Foucault, coloca que: 


\section{hevigtg ant paltg}

\} A INVENÇÃO DO DISPOSITIVO DA TRANSEXUALIDADE - SANTOS, M. F. L. \}

A filosofia de Foucault muitas vezes se apresenta como uma análise de "dispositivos" concretos. Mas o que é um dispositivo? Em primeiro lugar, é uma espécie de novelo ou meada, um conjunto multilinear. É composto por linhas de natureza diferente e essas linhas do dispositivo não abarcam nem delimitam sistemas homogêneos por sua própria conta (o objeto, o sujeito, a linguagem), mas seguem direções diferentes, formam processos sempre em desequilíbrio, e essas linhas tanto se aproximam como se afastam uma das outras (DELEUZE, 1990, p.1).

Percebe-se, dessa forma, que o dispositivo funciona como uma maquinaria que captura nas suas engrenagens sujeitos e corpos de forma plural, heterogênea e difusa. Não constitui um elemento fechado, mas um conjunto de diferentes linearidades que se articulam e rearticulam constantemente, conservando, no seu interior, a característica das tensões e das contradições. O dispositivo é, por excelência, contraditório, pois desvela o jogo paradoxal que se estabelece entre sujeitos e normas, revelando as "sedimentações" e as "fissuras" constituintes. Assim, compõe-se tanto por enunciados, discursos e falas como por ações e práticas, não se configurando nem em sujeito ou objeto, mas num" regime" de enunciações "que é necessário definir em função do visível e do enunciável, com suas derivações, suas transformações, suas mutações. E em cada dispositivo, as linhas atravessam limiares em função dos quais são estéticas, científicas, políticas etc." (DELEUZE, 1990, p. 2).

A ideia da transexualidade, enquanto dispositivo, reflete um conjunto de saberes que, através de relações e práticas de poder, estabeleceram sobre os corpos, o sexo e a sexualidade toda uma organização conceitual e prática que permitiu e legitimou a transexualidade como um fenômeno por excelência do âmbito médico, principalmente psiquiátrico. A genealogia desse processo encontra ressonância no dispositivo da sexualidade e na força da Scienta Sexualis a partir dos séculos XVIII e XIX.

\section{A Medicalização do Corpo e da Sexualidade}

A construção do dispositivo da transexualidade deve ser compreendida em um contexto de medicalização do corpo individual e social durante os séculos XVIII e XIX. É no âmbito da medicina, principalmente da Psiquiatria e no esteio da construção das perversões, que a gênese da transexualidade enquanto patologia inscreve-se historicamente. Coadunando estratégias de poder e campos de saberes, a etiologia das perversões tornou-se uma das preocupações centrais no campo da medicina. Esse processo, denominado de apropriação médica, foi central nos discursos e práticas sobre os comportamentos designados como perversos. Medicalizar o inoportuno passou a ser uma das preocupações do século XIX.

A homossexualidade foi o comportamento sobre o qual tanto o campo médico quanto o jurídico se debruçou como lócus de observação e intervenção. O trabalho de Kraft-Ebbing foi uma das principais obras cuja característica fundamental consistiu na construção e caracterização de diferentes patologias relacionadas aos comportamentos sexuais. Seu Psycopatia Sexuallis, publicado em 1886, é o primeiro 


\section{ReVistg all pgutg}

\} A INVENÇÃO DO DISPOSITIVO DA TRANSEXUALIDADE - SANTOS, M. F. L. \}

estudo organizado no âmbito médico sobre a sexualidade. Construindo diferentes tipologias, o autor procurou em linhas gerais classificar e caracterizar os comportamentos homossexuais.

As discussões apresentadas por Michel Foucault, principalmente na obra História da Sexualidade - a vontade de saber, constituem uma referência na compreensão do dispositivo da sexualidade, pois a apresenta e a discute, retirando-a de sua condição naturalizada, situando-a enquanto um "dispositivo" histórico formado a partir de uma rede de saber e poder que tomou os corpos dos indivíduos como espaço privilegiado de controle, produção de verdades e resistências.

A sexualidade é o nome que se pode dar a um dispositivo histórico: não à realidade subterrânea que se apreende com dificuldade, mas à grande rede da superfície em que a estimulação dos corpos, a intensificação dos prazeres, a incitação ao discurso, a formação de conhecimentos, o reforço dos controles e das resistências, encadeiam-se uns aos outros, segundo algumas estratégias de saber e de poder (FOUCAULT, 1997, p. 100)

Partindo da ideia de dispositivo de aliança baseado no matrimônio, no parentesco, na transmissão de nomes e bens, o autor constatou a presença, cada vez maior na modernidade, do dispositivo da sexualidade caracterizado pela produção, incitação e proliferação do falar sobre e do controle dos corpos e sexualidades. Com a construção do dispositivo da sexualidade, a partir da modernidade, foi possível perceber como os indivíduos, seus corpos e suas sexualidades foram capturados nas teias do saber/poder. O biopoder (poder sobre a vida) tornou-se o modelo contemporâneo de produção e controle de subjetividades. Foi, a partir desse contexto, que a transexualidade gradativamente transformou-se em um objeto próprio, com características particulares e com a singularidade de patologia.

\section{Emergência e visibilidade das experiências trans}

Dissertar sobre a transexualidade é discutir como a cultura ocidental tem construído categorias como corpo/sexo/sexualidade. Sua visibilidade é um fenômeno contemporâneo. Nas últimas décadas, várias (os) transexuais ganharam projeção, alargando as fronteiras do gênero estabelecidas pela dicotomia feminino/masculino.

Sem discorrer muito sobre os antecedentes discursivos da transexualidade, vale ressaltar que suas abordagens estendem-se a narrativas tradicionais, principalmente mitológicas, filosóficas e históricas. Diferentes mitologias evocam a possibilidade de inversão de papéis de gênero. Da mitologia greco-romana, como o mito de Tirésias (GREEN, 1975; SAADEH, 2004), ao panteão africano e hindu, diferentes entidades míticas incorporam a possibilidade tanto de alargamento quanto de inversão de gênero. Nas discussões filosóficas é clássico o Banquete, de Platão, onde Aristófanes discorre sobre o fenômeno da androginia.

No entanto, tomando a atualidade do fenômeno, Castel (2001) define a transexualidade como uma síndrome complexa caracterizada pelo sentimento intenso de não pertencimento ao sexo anatômico, sem por isso manifestar distúrbio delirante. 


\section{hevista all pautg}

\} A INVENÇÃO DO DISPOSITIVO DA TRANSEXUALIDADE - SANTOS, M. F. L. \}

Dessa conceituação é possível perceber duas trajetórias epistemológicas que a transexualidade vai assumir a partir da segunda metade do século XX. A primeira delas refere-se ao seu afastamento dos denominados distúrbios delirantes, como a psicopatia e a esquizofrenia. O outro polo caminhou gradativamente para o afastamento das explicações de bases orgânicas e fundamentadas nas discussões e investigações com os intersexuados. Esse movimento é importante na medida em que a transexualidade ganhou especificidade, tipologia, características e condução terapêutica próprias, presentes nos centros de referência e nas equipes profissionais específicas para o tratamento da transexualidade.

A saída da transexualidade do campo das perversões constituiu um fato gradativo e historicamente construído. Os estudos da sexologia, principalmente no éthos alemão na passagem do século XIX para o século XX, foram fundamentais na despatologização da homossexualidade e na contribuição da construção da ideia de transexualidade. Os trabalhos de Magnus Hirschfeld foram relevantes nesse processo. A criação do Instituto para o Estudo da Sexualidade em Berlim em 1919 é um marco nas pesquisas e lutas em relação à questão da sexualidade, principalmente da homossexualidade. É na sua obra Die Travestiten, publicada em 1910, que o termo transexual aparece pela primeira vez (CASTEL, 2001; SAADEH, 2004; ARÁN, 2006).

O importante nesse processo foi o fato de que as definições ligadas às "sexualidades desviantes" deixavam de ser meramente explicadas por valores morais e passavam a fazer cada vez mais parte do âmbito médico. Dessa forma, traçar a genealogia da transexualidade é fundamentalmente mapear o campo médico expresso através da psiquiatria, da endocrinologia e acompanhado pelas abordagens da psicologia e da psicanálise.

Os discursos em torno da transexualidade foram se constituindo através de um movimento que ao mesmo tempo em que promovia uma relativização das perversões construía outras categorias medicalizáveis. O que destoa, no caso principalmente da transexualidade, é o fato de que os sujeitos terão uma participação fundamental nesse processo na medida em que as demandas e falas dos transexuais será o material principal para os discursos e práticas médicas.

Durante o século XX, principalmente a partir da segunda metade, o esforço de profissionais do campo médico e psicológico foi na construção e definição do que viria a ser o fenômeno da transexualidade. Alguns marcos referenciam esse processo. Inicialmente as discussões e investigações em torno da intersexualidade ${ }^{1}$ foram o movimento propulsor tanto de discussões quanto de investigações empíricas. Foi a partir de inúmeros casos e intervenções clínicas com indivíduos intersexuais que a clínica da transexualidade começou a ser definida e especificada.

Outro marco nessa construção foram as discussões, no âmbito da Sociologia Funcionalista Norte-Americana, das categorias de sexo, gênero e papéis sexuais,

\footnotetext{
${ }^{1} \mathrm{O}$ termo intersexualidade é tomado aqui no sentido de designar um conjunto de atores sociais cujos corpos e subjetividades são marcados por ambiguidades nas genitálias. Sandrine $(2008$, p.110) nos coloca que "na esfera médica, em 1917 o termo 'intersexualidade' foi utilizado provavelmente pela primeira vez no sentido de fazer referência 'a uma gama de ambiguidades sexuais, incluindo o que antes era conhecido como hermafroditismo'".
} 


\section{ReVistg all pgutg}

\} A INVENÇÃO DO DISPOSITIVO DA TRANSEXUALIDADE - SANTOS, M. F. L. \}

cujos esforços se concentraram em delimitar a fronteira entre o mundo da "natureza" e o mundo da "cultura"2.

Esses dois movimentos coadunaram-se na tentativa de produzir discursos e intervenções sobre a transexualidade. Assim, a cartografia transexual explode através de diferentes concepções e explicações. Desde uma psicose, uma desordem narcísica, o resultado de uma foraclusão do nome do pai ou uma disforia de gênero até as explicações de ordem sociocultural e midiática, a arena dos debates mostra-se profícua e polêmica (CECARELLI, 1998). Da ideia de uma psicopatia ao conceito contemporâneo de disforia de gênero ${ }^{3}$, diversos meandros acompanham a história da transexualidade, cujas produções discursivas e práticas de poderes se constituíram na tentativa de achar o fundamento último e, muitas vezes, único do que vem a ser a transexualidade (CECCARELLI, 2003).

No entanto, essas discussões não ficaram apenas no campo conceitual. Diversas intervenções cirúrgicas começaram a se constituir nas primeiras décadas do século XX. Em 1912, o médico Steinach tentou implantar ovários em um sujeito do sexo masculino. Em 1921, Felix Abraham realizou uma cirurgia em "Rudolph", tornando esse o primeiro caso de um transexual redefinido (CASTEL, 2001; SAADEH, 2004; ARAN, 2006). Técnicas como a vaginoplastia e a faloplastia se tornaram mais populares principalmente após a Segunda Guerra Mundial. A descoberta e o uso dos hormônios também foram extremamente relevantes e decisivos para a produção do fenômeno da transexualidade. O uso dos mesmos possibilitou avanços significativos na construção dos atributos do sexo e gênero oposto ao sexo biológico. Além disso, diversas teorias emergiram na tentativa de relacionar e explicar o fenômeno da transexualidade tendo sua origem na questão hormonal e no desenvolvimento cerebral.

Atualmente, a transexualidade é conhecida como Transtorno de Identidade de Gênero, denominação que ganhou legitimidade no Diagnostic and Statistic Manual of Mental Disorders - DSM-IV -, no qual a transexualidade passou a ser considerada um Transtorno de Identidade de Gênero (F64.x) com características diagnósticas definidas, principalmente uma identificação com o gênero oposto e um desconforto com o próprio corpo. Em relação ao CID-10, a classificação da transexualidade aparece dentro dos Transtornos de Identidade de Gênero (F64), que se encontram entre os Transtornos de Personalidade e Comportamento. Ainda segundo o CID-10, também podem ser considerados transtornos o travestismo, transtornos de identidade sexual na infância e outros transtornos de identidade sexual. Outros campos de conhecimento denominam como neurodiscordância de gênero ou, ainda, Síndrome de Benjamim, como é conhecida nos Estados Unidos (RANSEY, 1998).

O conceito "transexualismo" foi utilizado inicialmente por Cauldwell, em 1949, no artigo Psychopatia Transexualis. Parafraseando a obra de Krafft-Ebing,

\footnotetext{
2 Segundo Castel (2001), a construção da problemática transexual ganha um novo impulso nos E.U.A., principalmente com o desenvolvimento de investigações sociológicas centradas na socialização dos ditos hermafroditas e transexuais, reavivando a tensão entre natureza e cultura.

${ }^{3}$ No plano da política da vida, o diagnóstico de "disforia" ou "transtorno" (ver DSM-IV) tem ressonâncias profundas e contraditórias, pois ao mesmo tempo em que assegura o acesso aos serviços de saúde trans, "receber o diagnóstico de transtorno de identidade de gênero - TIG - é ser, de certa maneira, considerado doente, errado, disfuncional, anormal e sofrer (...) certa estigmatização em consequência desse diagnóstico" (BUTLER, 2009).
} 


\section{hevistg em pautg}

\} A INVENÇÃO DO DISPOSITIVO DA TRANSEXUALIDADE - SANTOS, M. F. L. \}

Psychopathia Sexualis, o texto apresentava e discutia o fenômeno da transexualidade. O autor assinalava o "poderoso desejo" dos indivíduos que insistiam em pertencer ao sexo oposto. Ao contrário de casos isolados, já ficava claro, ainda na primeira metade do século XX, que o número de transexuais chegava a milhares: "Thousands of cases exist". Nesse artigo, o autor definiu a transexualidade como uma psicopatia, uma psicopatia transexual caracterizada pelo forte desejo de pertencimento ao sexo oposto. Para tanto, discorre em seu artigo sobre um caso clínico de uma fêmea nascida "normal" que insistia em pertencer ao sexo masculino. É possível perceber no artigo de Cauldwell uma forte influência da Psiquiatria, principalmente das psicopatias. O caso do "Conde", como denomina a mulher que o procurou, revelou, na análise do autor, elementos que configuravam um comportamento "anormal", "confuso" e "inadaptável" às normas sociais. Preso à separação entre os intersexuais e os transexuais, Psychopatia Sexualis é um elemento importante na construção do dispositivo da transexualidade, evidenciando a tentativa de construção de tipologias bem como de definição de campos de saberes.

A questão das intervenções cirúrgicas é um dos elementos centrais na consolidação do dispositivo da transexualidade Em 1952, foi documentada e se tornou pública a primeira cirurgia para adequação do sexo na cidade de Copenhague, Dinamarca: o ex-soldado americano Georges Jorgensen passava a ser Cristine Jorgensen (FRIGNET, 2002; RANSEY, 1998; VIEIRA, 1996; PERES, 2001; CASTEL, 2001; CHILLAND, 2003). Esse caso, conhecido como o "ato fundador da transexualidade", se diferencia pelo fato de que a partir da intervenção em Georges Jorgensen a terapêutica da transexualidade coadunou a transformação cirúrgica e tratamentos hormonais - a transexualidade deixou de estar inscrita nas patologias individuais, ganhando visibilidade (FRIGNET, 2002, p. 26).

Emergem nas literaturas termos como disforia, psicose, neurodisforia, perturbação mental, sofrimento psíquico, entre outras classificações cujos diagnósticos aparecem, na maioria das vezes, como "um vetor de patologização e de estigma, o qual muitas vezes acaba por atribuir uma patologia ao paciente sem questionar as questões históricas, políticas e subjetivas de psiquiatrização da condição transexual" (ARÁN; ZAIDHAFT; MURTA, 2005, p.17). É nessa arena profícua em abordagens que produções discursivas e estratégias de poder se constituem enquanto objeto de discursos, investigações e práticas.

\section{Henry Benjamin e "o fenômeno transexual" - a consolidação da transexualidade no éthos médico}

Henry Benjamin constitui uma das principais referências na genealogia da transexualidade. Alemão e Judeu, emigrou para os Estados Unidos no começo do século XX. No campo da endocrinologia começou a desenvolver pesquisas e elaborar ideias em torno do sexo e suas possíveis configurações.

Em 1953, publicou a obra $O$ fenômeno transexual, na qual além de definir e classificar a transexualidade conferiu-lhe especificidade, definindo seus contornos em relação ao transvestitismo, à homossexualidade e ao hermafroditismo, além de estabelecer uma condução terapêutica que iria se transformar numa referência na segunda metade do século XX. 


\section{ReVistg all pgutg}

\} A INVENÇÃO DO DISPOSITIVO DA TRANSEXUALIDADE - SANTOS, M. F. L. \}

Suas pesquisas o levaram a elaborar uma tipologia referente aos vários tipos de sexos. É no âmbito do denominado sexo psicológico que o autor começa a problematizar o fenômeno da transexualidade, no qual transexuais seriam indivíduos que não possuíam anomalia congênita (separando-os do hermafroditismo), mas apresentavam um distanciamento entre o sexo de nascimento e o sexo com o qual se identificavam. Definidos como "transexuais verdadeiros", esses sujeitos apresentavam um desejo de ser do outro sexo, de pertencer e viver todo o tempo como uma pessoa do sexo oposto ao de seu nascimento.

O desejo dos pacientes aparece em suas análises como um elemento imprescindível tanto para produzir a síndrome da transexualidade quanto para trazêla ao âmbito médico, transformando-a fundamentalmente numa preocupação clínica, principalmente com as intervenções cirúrgicas como a única solução para o sofrimento dos transexuais. A obra de Benjamim assinala e legitima a entrada da transexualidade nos discursos e práticas médicas, projetando visibilidade e legitimidade do campo. A partir da década de 1970, a transexualidade passou a compor toda uma discussão e normatização psiquiátrica que acabou por legitimar a criação de inúmeros centros de tratamento. Ainda em 1969, foi realizado em Londres o primeiro congresso da Harry Benjamin Association. Em 1977, essa entidade teve seu nome mudado para Harry Benjamin Internacional Gender Dysphoria Association (HBIGDA), assumindo a transexualidade como uma disforia de gênero. A HBIGDA tornou-se a maior referência tanto na condução do diagnóstico quanto nas condutas terapêuticas das pessoas transexuais no mundo inteiro (BENTO, 2006).

\section{John Money - A identidade e o papel sexual}

Os trabalhos de John Money apresentam uma contribuição sine qua non na discussão da transexualidade. No âmbito do contexto americano, influenciado pelas discussões da sociologia americana na década de 1960 e à frente das pesquisas realizadas no John Hopkins Hospital, Money, juntamente com uma equipe de renomados pesquisadores, construiu uma discussão em torno do conceito de identidade e papel sexual, instaurando, no âmbito médico, o debate sobre os comportamentos sexuais para além da dimensão biológica do sexo. Nesse contexto, a criação em 1966 da primeira Clínica de Identidade Sexual do John Hopkins Hospital, através da "unidade de pesquisa psico-hormonal", foi fundamental na discussão e formulação das ideias em torno do conceito de identidade e papel sexual. Composta por uma equipe multidisciplinar de especialistas/pesquisadores (sociólogos, geneticistas, embriologistas, psicólogos, psiquiatras, cirurgiões), a Clínica de Identidade Sexual centrou seus trabalhos em torno de homossexuais, travestis, transexuais e intersexuais. A Clínica de Identidade Sexual do John Hopkins foi um dos principais campos de pesquisas, investigações e formulações em torno da questão da sexualidade, constituindo um território relevante na coadunação de saberes/poderes e produção do dispositivo da transexualidade.

A transexualidade começa a emergir enquanto especificidade caracterizandose como um erro de identidade de gênero, cuja característica principal era uma discrepância entre o sexo atribuído e a identidade de gênero expressa através de um forte desejo de redefinir o sexo. 


\section{hevistg e.tI pautg}

\} A INVENÇÃO DO DISPOSITIVO DA TRANSEXUALIDADE - SANTOS, M. F. L. \}

Na obra Os papéis sexuais, Tucker e Money (1981) expõem de forma detaIhada o que designam como identidade e papel sexual. Definem a formação da identidade sexual como algo imprescindível na vida do ser humano, ou seja, seria o sentimento de pertencimento ao masculino ou feminino. A incorporação do conceito de identidade ao âmbito clínico permitiu pensar e explicar a questão da intersexualidade e da transexualidade, incorporando a dimensão social aos comportamentos sexuais. No bojo dos debates em torno da relação natureza/cultura, o autor constrói suas reflexões no diálogo entre os aspectos inatos e culturais. É na fissura entre a ideia de um determinismo sexual biológico e a ideia de que o comportamento sexual é modelado culturalmente que o conceito de identidade sexual é construído no seu pensamento como a maneira de responder aos inúmeros intersexuais atendidos no John Hopinks, cuja tese sustentada defendia a ideia de que a socialização era fundamental na constituição da identidade e do papel sexual a ser desenvolvidos por esses sujeitos. Esse processo foi decisivo na construção da transexualidade não apenas na dimensão clínica, mas psíquica, contribuindo para a produção de "verdades" que fundamentava a clínica da transexualidade.

\section{Robert Stoller - Para além da noção de sexo: a noção de gênero}

Na construção do dispositivo da transexualidade, as pesquisas e trabalhos de Robert Stoller são fundamentais para cartografar a história da transexualidade, suas tipologias, conduções clínicas e terapêuticas. Assim, tanto a obra Sex and Gender (1969) quanto A experiência transexual (1982) constituem marcos na teorização do que designamos sexo, gênero, papel e identidade sexual.

A experiência Transexual, publicada em 1975, é muito mais do que uma discussão teórica. Baseado em diversas pesquisas e investigações clínicas, Stoller vai definir e caracterizar o fenômeno a partir dos pacientes que trabalhou durante suas investigações. Assim, o primeiro passo foi a retirada do transexualismo da categoria das perversões, definindo-o como uma "desordem pouco comum, na qual uma pessoa, anatomicamente normal, sente-se como membro do sexo oposto e, consequentemente, deseja trocar seu sexo, embora suficientemente consciente de seu verdadeiro sexo biológico"(STOLLER, 1982, p. 2). Dessa forma, reafirma o lugar do transexual numa tipologia e numa caracterização próprias, que definem a sua especificidade em relação, principalmente, aos travestis.

Partindo dessa singularidade, traça uma explicação dos fatores que contribuem para a produção da transexualidade. Onde começaria a construção de uma identidade transexual? Essa é uma pergunta fundamental para compreender a gênese e consolidação desse comportamento. Para Stoller, desde os primeiros anos de vida as influências culturais e parentais passam a modelar a sexualidade das crianças. Entender o fenômeno da transexualidade é entrar pelo mundo dos valores e das referências parentais. Retirado do imperativo biológico, a sexualidade aparece como um traço de comportamento cuja importância parental é condição sine qua non no seu desenvolvimento. Dessa forma, o aprendizado, o treinamento, será o processo pelo qual os sujeitos constituem sua sexualidade e identidade.

A família e principalmente a figura da "mãe" do/a transexual aparece como tema central na discussão. O desenvolvimento da transexualidade podia, a seu ver, 


\section{ReVistg all pgutg}

\} A INVENÇÃO DO DISPOSITIVO DA TRANSEXUALIDADE - SANTOS, M. F. L. \}

ser mensurada em relação aos valores familiares. Nesse sentido, o autor vai buscar nos casos clínicos, na sua observação e em similaridades os exemplos que permitiram "universalizar" os modelos parentais nos quais a figura da mãe aparece como principal protagonista. Essa relação era definida por características como proximidade, intensidade, horas incontáveis de intimidade, olhares profundos, braços que embalam, entre outras que são colocadas numa posição extrema na relação mãe/filho. Essas características passam a universalizar e caracterizar o "transexual" e sua relação com a imagem da mãe. O clássico conflito edipiano que deveria ocorrer de forma normal no processo de desenvolvimento, principalmente nos meninos, sofre mudanças no rumo de sua trajetória e seu desejo (STOLLER, 1982).

A figura do pai também aparece como contraposição à imagem da mãe. Assim, o pai é visto como ausente, "evita envolvimentos emocionais com sua esposa ou com o paciente e não se apresenta como um rival pela afeição da mãe ou como um modelo para identificação masculina" (STOLLER, 1982, p.95). Tomando essas características parentais como fundamentais, Stoller vai levar o modelo como "causa" fundamental na construção da identidade transexual, desenvolvendo uma das explicações que sustentou e ainda sustenta muitas afirmações sobre as experiências trans.

Esses três autores, suas investigações, publicações e a formação de grupos de pesquisa formam domínios de saber e poder que foram decisivos na construção de regimes de verdades que sustentam a transexualidade enquanto patologia. Esses modelos de explicações acabaram por reduzir experiências e modos de vida à dimensão clínica.

\section{As tecnologias de gênero}

Outros movimentos conceituais que têm contribuído para compreensão do dispositivo da transexualidade são as discussões sobre a relação tecnologias e transexualidade. Hausman (1995) destaca que entre os anos de 1920 e 1950, uma série de artigos sobre a endocrinologia e sua relação com o comportamento humano foram escritos tanto por médicos como por jornalistas que se habilitavam nas incursões no campo médico. Esse período foi de fundamental relevância na construção do dispositivo da transexualidade, no qual a endocrinologia, seja como um campo de conhecimento ou uma prática médica, contribuiu para a emergência e consolidação do fenômeno. Nesse período, a publicação e a popularização de inúmeras teses garantiram o acesso ao aparato discursivo e médico Esse processo acabou contribuindo para que inúmeros indivíduos se percebessem enquanto "sujeitos" no processo de construção da transexualidade. Para a autora, a emergência da transexualidade, na $1{ }^{-a}$ metade do século XX, dependeu do desenvolvimento da endocrinologia e da cirurgia plástica como práticas discursivas e tecnológicas, sendo impossível dissociar o entendimento da transexualidade dos suportes tecnológicos.

Nesse aspecto, a endocrinologia transformou-se num discurso científico culturalmente forte. Os avanços nesse campo ganharam importância não apenas no âmbito médico, mas ocuparam o tecido social através de revistas e publicidade que divulgavam as descobertas e maravilhas do mundo dos hormônios. À medida que as pesquisas avançavam, entre os anos de 1930 e 1950, a partir da sintetização 


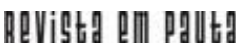

\} A INVENÇÃO DO DISPOSITIVO DA TRANSEXUALIDADE - SANTOS, M. F. L. \}

cada vez maior dos hormônios, principalmente os hormônios sexuais, uma crescente indústria química e biomolecular se desenvolveu.

Nesse sentido, Hausman (1995) destaca que é impossível entender o fenômeno da transexualidade sem relacioná-lo às transformações tecnológicas. Nesse contexto, a tecnologia médica foi o ponto central para o estabelecimento das condições necessárias para a emergência e consolidação da transexualidade. Sendo assim, é impossível dissociar seu entendimento dos suportes tecnológicos e ideológicos dos discursos e práticas médicas.

Arán e Murta (2009, p. 26), resgatando as ideias de Bernice Hausman, dispõem que, segundo a autora,

A emergência da transexualidade na metade do século XX estaria diretamente associada ao desenvolvimento da tecnologia, particularmente da Endocrinologia e da cirurgia plástica. Para a autora, embora pareça evidente, a relação entre a tecnologia médica, a prática médica e o advento da possibilidade de mudança de sexo não estaria sendo suficientemente destacada nos estudos de gênero, os quais, na sua concepção, entendem a transexualidade como uma inadequação entre sexo e gênero. De acordo com seu argumento, o que define a experiência transexual é menos a percepção dessa incoerência e mais a necessária e fundamental relação conceitual e material desses sujeitos com o discurso e a prática médica. A partir dessa concepção, transexuais só adquirem reconhecimento no momento em que procuram o tratamento, sendo que sua posição subjetiva dependeria de uma relação necessária com a definição médica e seu discurso.

Dessa forma, o desenvolvimento da endocrinologia e concomitante das cirurgias plásticas representou uma mudança nos rumos que a transexualidade passaria a configurar a partir de então, formatando elementos que perfazem, reforçam e naturalizam as experiências trans.

\section{Considerações finais: $o$ dispositivo e as subversões normativas}

Partindo das questões levantadas, a construção da norma transexual emergiu a partir de critérios científicos e clínicos, procedimentos mensuráveis, esquadrinhamentos de corpos e subjetividades. Esse processo configurou-se tanto através da construção do diagnóstico de transtorno de identidade de gênero quanto do desenvolvimento de uma condução terapêutica que marca consideravelmente os modos de vida das pessoas que vivenciam as experiências trans. É preciso ressaltar a relação que o diagnóstico tem com as vidas das pessoas trans, principalmente no que se refere à autonomia dos sujeitos, bem como o que significa para os mesmos viver sob a denominação de um portador de transtorno de gênero (BUTLER, 2009).

Por outro lado, o discurso da diferença começa a marcar as vozes transexuais, seja em oposição à ideia de anormalidade ou a outras questões cujos sujeitos tornam- 


\section{ReVistg all pgutg}

\} A INVENÇÃO DO DISPOSITIVO DA TRANSEXUALIDADE - SANTOS, M. F. L. \}

se porta-vozes de si mesmos, seus problemas, angústias, percepções, enfim as experiências de viver a condição da transexualidade através de diferentes movimentos, sejam institucionalizados ou não. Nessa perspectiva, são diversas as formas de falar e expressar as diferenças (de sexo, gênero e sexualidade) por parte das (os) transexuais, resgatando os saberes localizados e a experiência trans, desvelando as possibilidades de vivenciá-la sem necessariamente ser caracterizada enquanto patologia. O movimento de despatologização que emerge e ganha força na contemporaneidade requer a compreensão da invenção da transexualidade cujas resistências encontram-se no âmbito do próprio dispositivo. 


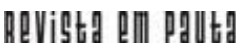

\} A INVENÇÃO DO DISPOSITIVO DA TRANSEXUALIDADE - SANTOS, M. F. L. \}

\section{Referências bibliográficas}

ARÁN, M. A transexualidade e a gramática normativa do sistema sexo-gênero. Revista Agora. Rio de Janeiro: n. 1, p. 49-63, jan-jun, 2006.

ARÁN, M; MURTA, D. Transexualidade e Saúde Pública no Brasil. Ciência \& Saúde Coletiva, Rio de Janeiro: v.4, n.14, p.1141-1149, 2009.

; ZAIDHAFT, S.; MURTA, D. Transexualidade e saúde: a experiência do HUCFF/UFRJ. No prelo.

.. Transexualidade: corpo, subjetividade e Saúde Coletiva. Psicologia \& Sociedade, Rio de Janeiro: v.1, n.20, p.70-79, 2005.

BENTO, B. A reinvenção do corpo: sexualidade e gênero na experiência transexual. Rio de Janeiro: Garamond, 2006.

BUTLER, J. Desdiagnosticando o gênero. Revista Physis, Rio de Janeiro: v. 19, n. 1, p. 96-126, 2009. Disponível em <http://www.scielo.br>. Acesso em 1o set. 2011.

CASTEL, P-H. Algumas reflexões para estabelecer a cronologia do fenômeno transexual (1910-1995). Revista Brasileira de História. São Paulo, v. 21, n. 41, p. 77-111, 2001.

CAULDWELL, D. O. Psychopathia transexualis. Revista Sexology, n.16, p. $247-$ 280, 1949. Extraído do The International Journal of Transgenderism, v. 5, n. 2, aprjun, 2001.

CECCARELLI, P. R. Transexualismo e caminhos da pulsão. Revista do Círculo Psicanalítico de Minas Gerais, ano XXV, 2003. Acesso em 03 jul, 2011.

. Transexualismo e identidade sexuada. In: VIVIANI, A. (org). Temas de Clínica Psicanalítica. São Paulo: Experimento, 1998.

CHILLAND, C. Le transexulisme: que sais-je? Paris: Puf, 2003.

DELEUZE, G. ¿Que és un dispositivo? In: Michel Foucault, filósofo. Barcelona: Gedisa, 1990.

FOUCAULT, M. Microfísica do poder. Rio de Janeiro: Graal, 2002.

1997 .

. História da sexualidade: a vontade de saber. 12. ed. Rio de Janeiro: Graal,

FRIGNET, H. O Transexualismo. Rio de Janeiro: Companhia de Freud, 2002.

GREEN, R. Mythological, Historical and cross: cultural aspects of transexualism. In: Transexualism and sex reassignment. Baltimore: The Jonh Hopkins University Press, 1975.

HAUSMAN, B. Changing sex: transsexualism, technology and the idea of gender. Durham: D. U. Press, 1995.

PERES, A. P. A. B. Transexualismo: o direito a uma nova identidade sexual. Rio de Janeiro: São Paulo: Renovar, 200.

RAMSEY, G.. Transexuais: perguntas e respostas. São Paulo: Summus, 1998. 


\section{heVistg all pgutg}

\} A INVENÇÃO DO DISPOSITIVO DA TRANSEXUALIDADE - SANTOS, M. F. L. \}

SAADEH, A. Transtorno de identidade sexual: um estudo psicopatológico de transexualismo masculino e feminino. São Paulo, Tese de Doutorado, Programa de Pós-Graduação em Psiquiatria da Faculdade de Medicina, USP, 2004, mimeo.

STOLLER, R. A experiência transexual. Rio de Janeiro: Imago, 1982. . Sex and gender. v. 1. New York: Science House, 1969.

TUCKER, P.; MONEY, J. Os papéis sexuais. São Paulo: Brasiliense, 1981.

VIEIRA, T. R. Mudança de sexo: aspectos médicos, psicológicos e jurídicos. São Paulo: Santos, 1996.

Recebido em 19 de setembro de 2011

Aceito para publicação em 15 de dezembro de 2011 